\title{
RANCANG BANGUN DAN PENGUJIAN TEKNIK MRC PADA PENERIMA TV DVB T2
}

\author{
Slamet Widodo' ${ }^{1)}$, Sri Anggraeni Kadiran' \\ ${ }^{1}$ Teknik Elektro \\ Politeknik Negeri Semarang \\ Email: maswied105@gmail.com
}

\begin{abstract}
Abstrak - Teknik maximal ratio combining (MRC) merupakan salah satu teknik combining diversity yang digunakan untuk mengatasi terjadinya fading pada sistem transmisi radio. Fading pada transmisi TV digital DVB T2 menyebabkan gambar berhenti dan suara terganggu. Dari penelitian sebelumnya menunjukkan bahwa secara simulasi, teknik MRC mempunyai kualitas paling baik dibanding teknik combining lainnya. Pada penelitian ini, telah dibuat rangkaian MRC dengan dua input. Sinyal yang datang dikuatkan kemudian masuk ke rangkaian penggeser fasa. Untuk menghindari pembuatan IC, proses combining dilakukan pada tingkat RF (radio frequency). MRC menggabungkan dua antena penerima TV yang berjarak $1 / 4 \lambda$. Hasil pengukuran di laboratorium menunjukkan bahwa sistem penerima yang dibuat berhasil menggabungkan dua input sinyal pada tingkat RF, dengan penguatan yang lebih besar. Pengujian penerimaan siaran TV digital DVB T2 di daerah semarang pada kondisi diam menunjukkan bahwa sistem dapat menerima seluruh stasiun pemancar TV digital DVB T2 di semarang dengan kualitas yang baik. Pada jarak $9 \mathrm{Km}$ dari stasiun pemancar, daya yang diterima sebelum menggunakan MRC - 77,3 dBm, setelah menggunakan MRC - 71,2 dBm.
\end{abstract}

Kata kunci : RF combining, diversity, digital TV receiver DVB T2, MRC

\section{PENDAHULUAN}

Beralihnya sistem siaran TV analog ke digital merupakan gerakan internasional, tak terkecuali negara kita. Migrasi ini tidak bisa dihindari, mau tidak mau kita harus siap siap beralih dari siaran TV analog ke TV digital. Negara tetangga kita seperti Singapura dan Malaysia telah lebih dulu melakukan migrasi. Kelebihan siaran TV digital antara lain memerlukan bandwidth yang lebih sempit dan gambar yang lebih jernih. Dengan teknik OFDM dan kompresi MPEG, satu kanal TV analog bisa digunakan untuk 8 kanal TV digital.

Penelitian untuk menyempurnakan siaran TV digital terus dilakukan, baik dari sisi pemancar maupun dari sisi penerima. Secara teori, kualitas gambar siaran TV digital lebih jernih dibanding TV analog. Pada siaran TV analog, jika sinyal penerimaan turun, kualitas gambar dan suara perlahan lahan turun, gambar yang diterima akan kabur dan buram. Pada siaran TV digital, selama kuat sinyal yang diterima diatas threshold, gambar akan selalu jernih dan suara jelas. Sebaliknya jika sinyal yang diterima kurang dari threshold, gambar berhenti atau tidak ada sinyal. ETSI sebagai organisasi pengembang TV digital, secara terbuka mengajak semua peneliti untuk mengembangkan dan menyempurnakan TV digital.

Terdapat beberapa standard siaran TV digital, yaitu DVB T, ATSC, DTMB, ISDB T dan DMB T. Pemerintah telah menetapkan standard TV digital yang digunakan di Indonesia adalah DVB T generasi kedua atau lebih dikenal sebagai DVB T2.
Pada penelitian ini telah dilakukan perancangan dan pembuatan tuner penerima siaran TV DVB T2 menggunakan teknik maximal ratio combining atau MRC. Teknik MRC ini telah digunakan oleh transmisi seluler untuk mengatasi fading. Pemakaian teknik MRC pada sistem siaran TV digital DVB T2, masih dalam penelitian. Oleh karena itu, penelitian yang dilakukan ini akan memberikan memberikan informasi tentang kualitas transmisi dari penerapan teknik MRC pada transmisi siaran DVB T2. Yang menarik, setelah selesai dibuat, alat ini diuji di daerah semarang yang bergunung-gunung dan banyak gedung bertingkat yang berpotensi terjadinya fading.

Penelitian-penelitian sebelumnya melalui simulasi dengan program MATHLAB menyatakan bahwa teknik MRC merupakan teknik diversity yang lebih baik dibanding teknik diversity selection diversity (SC). Namun teknik MRC lebih sulit dan lebih kompleks dibuat.

Tujuan khusus penelitian ini antara lain merancang dan membuat tuner penerima DVB T2 menggunakan teknik maximal ratio combining $(M R C)$, merancang dan membuat antena mikrostrip untuk menerima siaran TV DVB T2. Setelah selesai dibuat dilakukan pengujian baik di laboratorium maupun di daerah siaran TV digital DVB T di semarang. Sedangkan tujuan umum penelitian ini untuk menghasilkan prototipe sistem penerima TV digital DVB T2 yang bisa dipasang di mobil yang sedang berjalan dengan kualitas penerimaan yang baik. Sebagai dokumentasi, akan menghasilkan karya ilmiah yang menjelaskan 
proses perancangan dan pembuatan prototipe tuner penerima TV digital DVB T2 beserta data data hasil pengujian.

Pada penelitian ini, proses combining dilakukan pada tingkat RF dengan menggunakan komponen yang ada di pasaran. Hal ini dilakukan karena jika dilakukan pada tingkat baseband seperti pada simulasi, realisasinya memerlukan pembuatan IC. Banyak penelitian yang berhenti pada tingkat simulasi dengan MATHLAB karena tidak ada industri pembuat IC.

Setelah dilakukan penelitian ini akan diketahui apakah sistem tuner penerima DVB T2 menggunakan teknik MRC mempunyai kualitas yang baik?. Apakah teknik combining pada tingkat RF bisa dilakukan?

Penelitian tentang TV digital DVB T yang menjadi acuan dalam penelitian ini antara lain, Dian WA[3] berjudul Analisa simulasi performance penggunaan OFDM pada sistem DVB $\mathrm{T}$, menyatakan bahwa guard interval $(G I)$ tidak banyak berpengaruh pada ISI (inter symbol interference) karena DVB $\mathrm{T}$ menggunakan estimasi kanal. Penelitian lain yang berjudul " $A$ performance study of DVB-T2 and DVB-T2-Lite for mobile reception" menyatakan unjuk kerja dari DVB T2 dan DVB T2 lite untuk menerima siaran TV digital saat kendaraan bergerak (Diego Asamo, 2014). Kemudian $R F$ combiner and DVB T2 received signal [1] yang menyatakan bahwa proses penggabungan atau combiner bisa dilakukan pada tingkat RF.

\section{METODE PENELITIAN}

Metode penelitian yang digunakan dalam penelitian ini antara lain, studi pustaka, perancangan, pembuatan dan pengujian . Dengan studi pustaka, masalah - masalah yang telah dirumuskan dapat dicari solusinya, Beberapa teknik dari hasil hasil penelitian orang lain yang terkait bisa dijadikan acun penyelesaian masalah, Perancangan dilakukan dengan landasan teori yang berlaku. Pembuatan rangkaian teknik MRC diversity dan antena mikrostrip berdasarkan hasil rancangan. Setelah selesai dibuat barulah dilakukan pengujian. Pengujian dilakukan dua kali, yakni dengan peralatan di laboratorium untuk menguji kerja rangkaian perbagian, dan penerimaan siaran TV digital DVB T2 di daerah semarang.

Dari studi pustaka diperoleh data bahwa teknik MRC merupakan teknik yang digunakan untuk mengatasi fading. Fading terjadi. Pada teknik diversity MRC sinyal yang diterima dari pemancar melalui antena antena penerima disamakan dulu phasenya, baru kemudian dijumlahkan seperti yang ditunjukkan gambar 1 . Berdasarkan prinsip teknik MRC diatas, tim peneliti melakukan perancangan tuner penerima TV DVB T2 menggunakan teknik MRC seperti yang ditunjukkan gambar 2 .

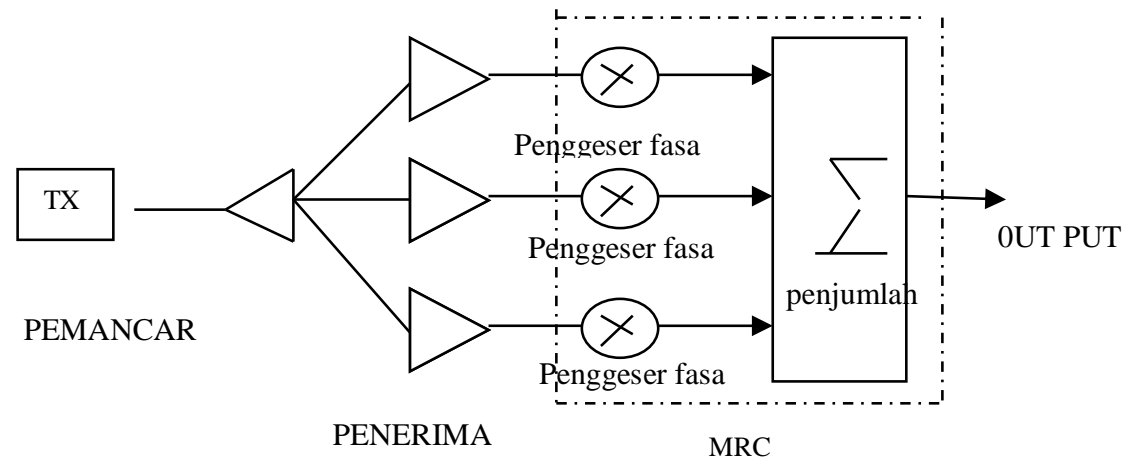

Gambar 1 Prinsip Teknik MRC diversity [2]

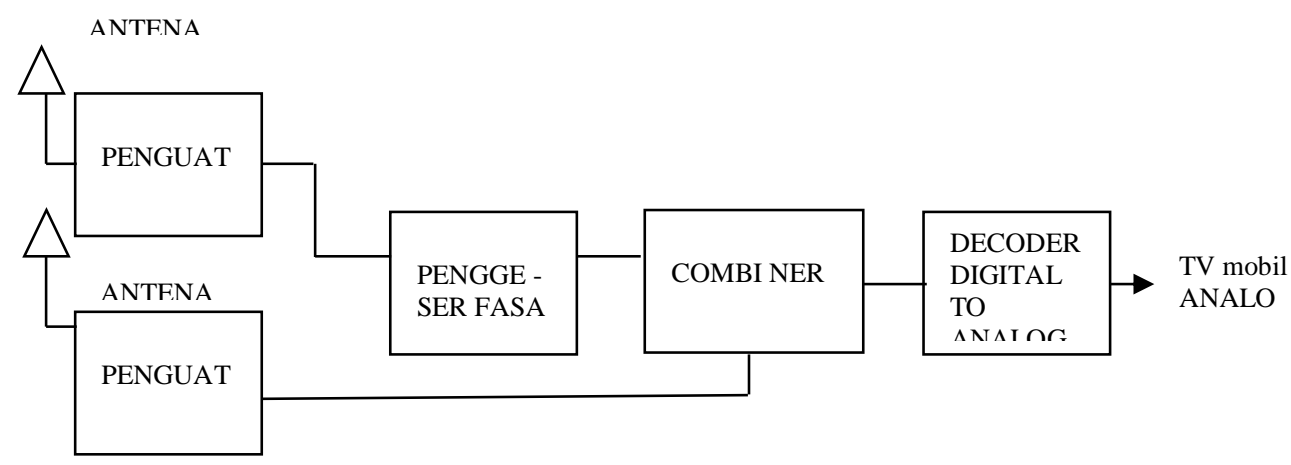

Gambar 2 Diagram Blok Rancangan Teknik MRC untuk Tuner Penerima TV DVB T2 
Antena yang digunakan adalah antena mikrostrip yang mempunyai bentuk kecil, ringan dan kuat sehingga mudah diletakkan didalam mobil. Penguat yang digunakan adalah penguat yang bekerja pada tingkat RF (radio frequency). Penguat ini diperlukan karena sinyal yang diterima sangat kecil, untuk mempermudah proses penggeseran fasa untuk input 1 dan tanpa digeser phasanya untuk input 2. Combiner RF akan menjumlah dua input tersebut jika sudah sama phasanya. Hasil penjumlahan ini kemudian diteruskan ke decoder digital to analog atau sering disebut STB (set top box) untuk penerima TV analog dan tanpa STB jika menggunaakan TV digital.

Penguat yang digunakan adalah penguat operasional THS 3202 yang mampu bekerja sampai frekuensi $1 \mathrm{GHz}$. Sehingga bisa digunakan untuk frekuensi tv UHF dan VHF. (spesifikasi THS 3202, 2015).

Rancangan rangkaian penguat ditunjukkan oleh gambar 3 .

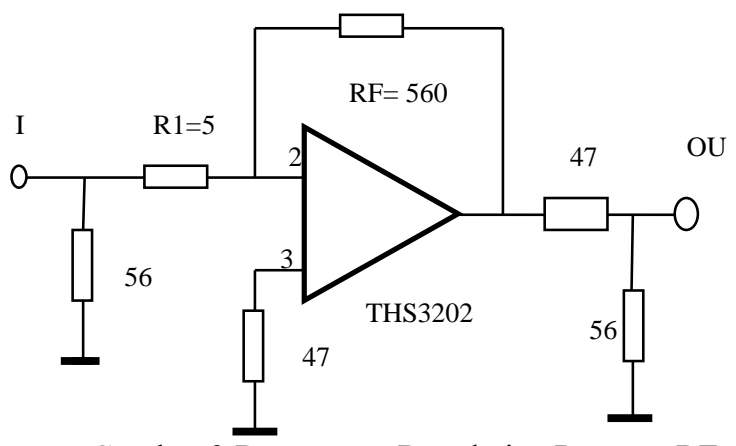

Gambar 3 Rancangan Rangkaian Penguat RF

Rangkaian penguat RF ini menggunakan penguat operasional yang dioperasikan sebagai penguat inverting. Penguatan $\mathrm{AV}=$ Vout $/$ Vin

$$
\mathrm{AV}=-\frac{\mathrm{RF}}{\mathrm{R} 1}
$$

Tanda - menunjukkan phase sinyal output berbeda phasa $180^{\circ}$ dengan phasa sinyal input

Rancangan rangkaian penggeser fasa ditunjukkan gambar 4.

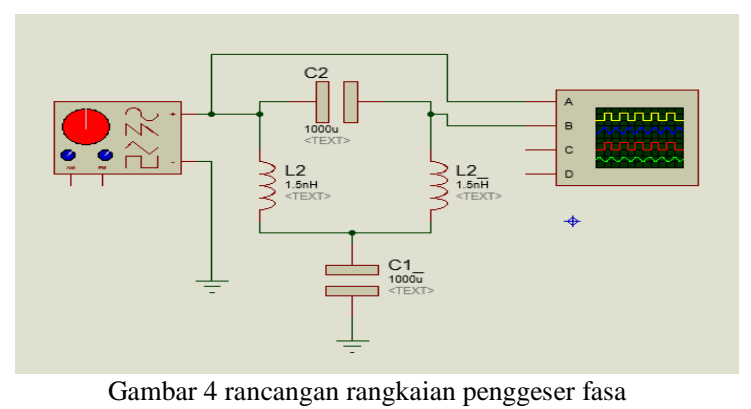

Nilai C2 dan L2 dihtung dengan menggunakan rumus

$$
\begin{aligned}
L 2 & =\frac{Z o \cdot \operatorname{Sin} \theta}{2 \pi \cdot F(1-\cos \theta)} \\
C 2 & =\frac{1}{2 \pi \cdot F \cdot Z o \cdot \operatorname{Sin} \theta)}
\end{aligned}
$$

Rancangan rangkaian combiner RF ditunjukkan gambar 5

IN

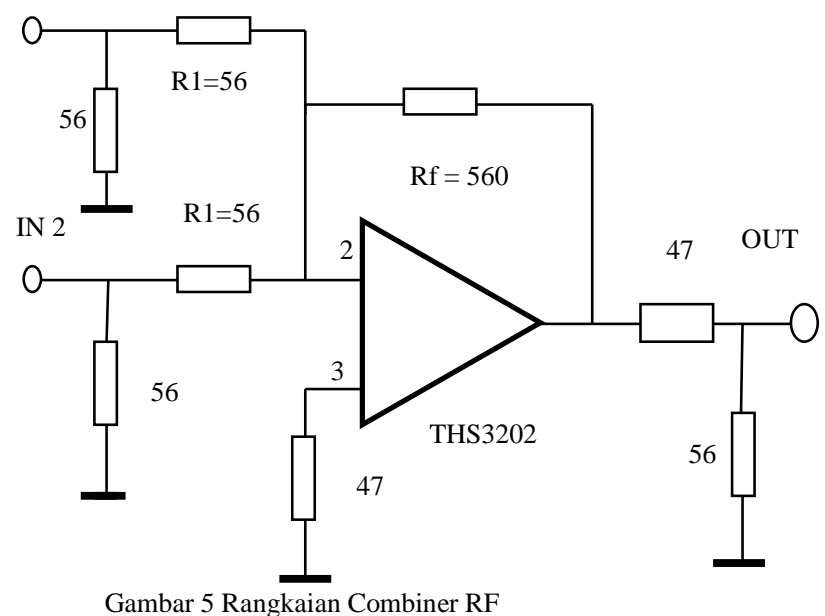

Vout $=-(\mathrm{V}$ in $1+\mathrm{Vin} 2) \frac{\mathrm{RF}}{\mathrm{R} 1}$

Decoder Digital to analog yang digunakan adalah decoder atau STB untuk tempat tinggal ataau diam dan catuannya berasal dari catu daya listrik atau PLN. Oleh karena itu untuk bisa digunakan menggunakan catu daya DC dari accumulator perlu dimodifikasi 


\section{HASIL DAN PEMBAHASAN}

Setelah perancangan, kemudian dibuat rangkaian tersebut pada rangkaian papan cetak PCB. Pembuatan MRC pada tingkat RF memerlukan ketelitian dan kesabaran. Beberapa kali terjadi ketidak telitian yang mengakibatkan rangkaian tidak mau bekerja seperti yang diharapkan. Selain itu rangkaian yang ditunjukkan pada rancangan perlu dimodifikasi dan ditambah komponen komponen lain agar bisa bekerja dengan baik. Pada setiap tingkat perlu ditambahkan rangkaian band pass filter (BPF) agar rangkaian benar-benar bekerja pada frekuensi yang diinginkan. Hasil penelitian ini bisa dilihat pada gambar 6.

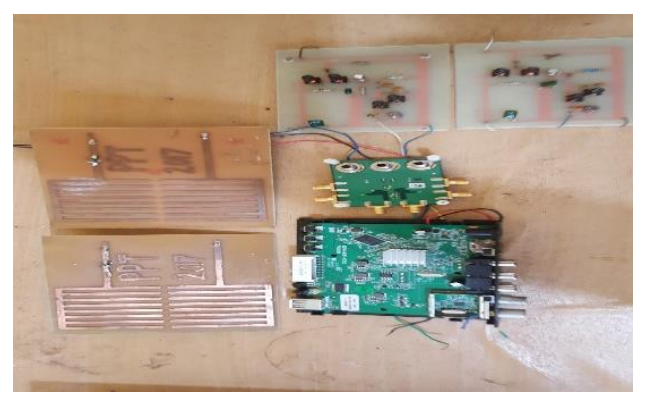

Gambar 6 Realisasi rangkaian tuner penerima TV DVB T2 menggunakan antena mikrostrip. Sebagai hasil penelitian

Kemudian dirangkaia dalam box untuk bisa digunakan di mobil. IC THS 3202 pada awalnya memerlukan dua sumber catu daya. Tetapi bisa dimodifikasi agar dapat bekerja dengan satu daya searah, sesuai yang tersedia di mobil. Gambar 7 menunjukkan box tuner penerima TV DVB T2 menggunakan MRC hasil penelitian

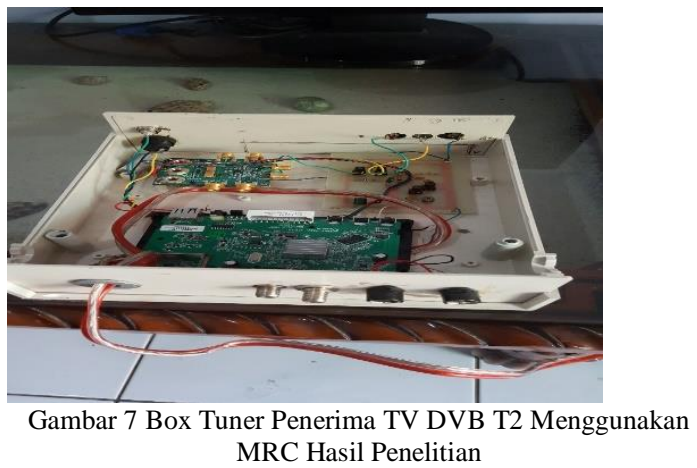

Untuk mengetahui apakah rangkaian yang dibuat ini bekerja dengan baik atau tidak, maka perlu dilakukan pengukuran dan pengujian. Pengukuran di laboratorium uruh rangkaian. untuk mengetahui kualitas kerja dari masing masing bagian. Sedangkan pengujian untuk menerima siaran TV digital DVB T2 di daerah semarang untuk mengetahui kualitas penerimaan alat. Baik dalam kondisi diam maupun kondisi berjalan.

Di Semarang pemancar TV digital yang telah beroperasi yaitu TVRI nasional, TVRI Jawa Tengah, TVRI budaya, TVRI olah raga, NET TV, Aspira TV, Nusantara TV dan TVKU.

Semua stasiun TV diatas menggunakan mux TVRI pada frekuensi $530 \mathrm{MHz}$ dan lebar BW $8 \mathrm{MHz}$. Pada kanal $530 \mathrm{MHz}$ ini suara maupun gambar benar-benar jernih, meski diterima saat diam dan berjarak 6,1 Km. Sedangkan Metro TV yang mempunyai metro TV HD dan metro TV smg tidak begitu kuat diterima, sehingga kadang bisa diterima, kadang tidak (suara putus putus).

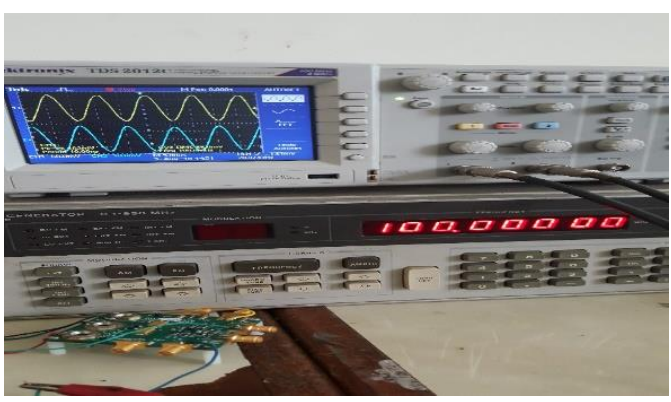

Gambar 8 Penguat RF dapat bekerja dengan baik pada frekuensi $100 \mathrm{MHz}$ (Penguatan 5 kali).

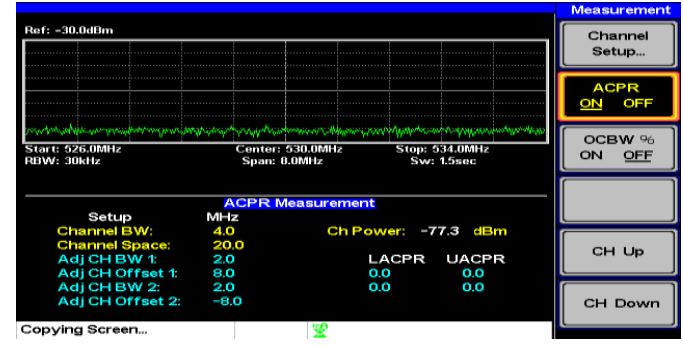

Gambar 9 Kuat sinyal yang diterima sebelum menggunakan tuner penerima DVB T2 (Kondisi diam jarak 6,1 km, -77,3 $\mathrm{dBm})$

Pengujian untuk menerima siaran TV digital DVB T2 di daerah semarang dimulai dari rumah ketua tim peneliti di jl Bendungan G 43 Payung Mas, Pudak Payung, Semarang. Yang berjarak 6,1 Km dari pemancar TV yang berada di Bukit Sari Semarang. Dengan menggunakan tuner DVB T2 yang telah dibuat dan dengan antena mikrostrip, Siaran dari pemancar yang tergabung pada mux TVRI seperti Nusantara TV, NET TV, Aspira TV, TVKU, dan empat pemancar TVRI bisa diterima oleh TV mobil dengan baik. . 


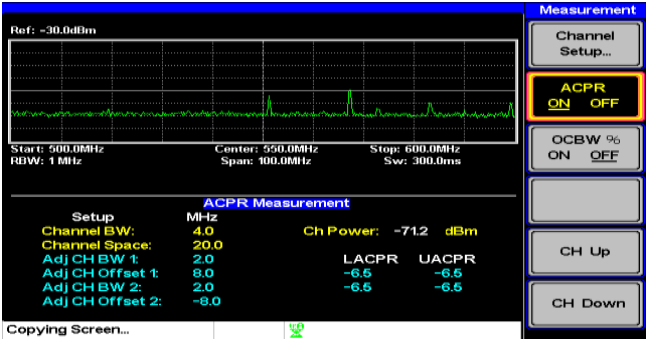

Gambar 10 Kuat snyal yang diterima saat menggunakan tuner penerima TV DVB T2

(Kondisi diam jarak 6,1 km, -71,2 dBm)

Dari hasil pengukuran sebelum dan sesudah menggunakan tuner penerima TV terlihat bahwa sinyal yang diterima naik dari $-77,3 \mathrm{dBm}$. menjadi - 71,2 dBm yang berarti mengalami kenaikan sebesar 6,1 dB.

\section{Pengujian Kondisi Berjalan}

Pengujian saat mobil berjalan dilakukan dengan memasang tuner penerima TV DVB T2 dan dikoneksikan dengan TV mobil, digunakan untuk menerima siaran TV yang dipancarkan dari stasiun pemancar di daerah Bukit Sari. Tempatnya yang tinggi menjadikan hampir semua pemancar TV berada di bukit sari.

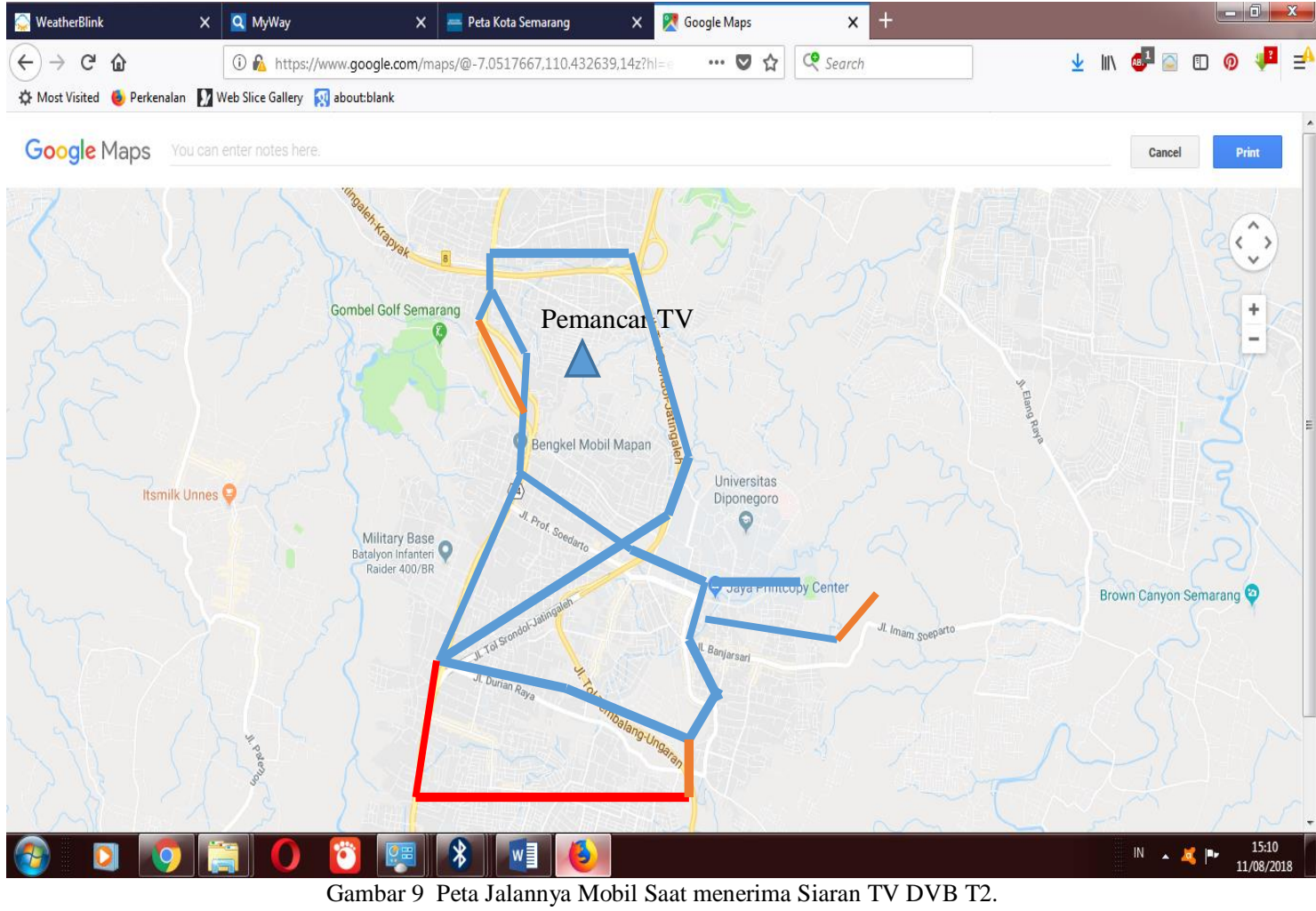

Pengujian dilakukan di sepanjang Jalan Prof Sudarto dari kampus undip sampai pertempatan Ngesrep Timur. Jl Setiabudi ke utara sampai Jatingaleh. Kembali keatas melalui tol sampai T $\forall$ oko ADA Srondol. Keluar tol melalui jalan duriian. Sinyal yang diterima dengan baik ditandai warna biru. Sinyal putus-putus di sekitar J1 karang rejo dan sepanjang gombel lama yang ditandai garis merah. Khusus di jl gombel lama, siaran yang diterima putus putus meskipun jaraknya dekat. Hal ini disebabkan kawasan gombel lama tertutup oleh bukit.

Pada saat mobil melaju di jalan tol naik dari Jatingaleh menuju Srondol, Kecepatan 40 s/d 50 masih bisa menerima dengan baik, tetapi diatas 50 $\mathrm{Km}$ perjam, siaran putus putus timbul tenggelam.

\section{SIMPULAN}

Dari penelitian yang telah dilakukan, bisa ditarik bebrapa simpulan. Secara umum tuner penerima TV digital DVB T2 menggunakan teknik MRC dan dengan antena mikrostrip berhasil dibuat. Tuner penerima TV ini berhasil menaikkan kuat sinyal yang diterima sebesar kurang lebih 6 dB. Namun demikian kualitas penerimaan masih sering putus bahkan tidak bisa menerima pada jarak tertentu. Kelemahan yang terjadi gain antena mikrostrip terlalu lemah. Perlu perbaikan antena mikrostrip dan sistem penerima secara keseluruhan 
JUST TI, Volume 11 Nomor 1, Januari 2019: 37-42

untuk dapat memperoleh hasil yang lebih baik. Saran tim peneliti, perlundicoba antena bentuk lain yang mempunyai gain lebih tinggi.

\section{REFERENSI}

[1] B Setyanto, Iswandi (2014). Combiner RF and DVB T2 signal receive, Resipository ugm.ac.id. Yogyakarta.

[2] Chadukar S, Bharmase, (2009), Performance evaluation of equalizers and different diversity techniques using OFDM, International journal of computer technology and electronic engineering, voll issue 3

[3] Dian W A (2011), Analisa simulasi performance penggunaan OFDM pada sistem DVB T, USU Medan 